can arise by further rotation about the $\mathrm{N}-\mathrm{C}$ bond. In this structure, the geometry of the planar DNP ring system is almost flat (Figure 13) with respect to the surface and the molecule is in its most extended form. Both $p$-nitro and o-nitro groups would then be oriented so that $\nu_{\mathrm{s}}\left(\mathrm{NO}_{2}\right)$ would have a very small $\alpha_{z z}$ component.

By analogy to SERS spectra of benzene, pyridine, and other planar ring compounds adsorbed on silver, the large enhancement of the Raman band assigned to the symmetrical ring-breathing mode located at $833 \mathrm{~cm}^{-1}$ for the DNP ring system, which was observed at concentrations $\geq 1 \mu \mathrm{M}$, can be indicative of either flat, side-on, or end-on orientation of the ring with respect to the surface. However, simultaneous SERS enhancement of the in-plane, $\nu_{s}\left(\mathrm{NO}_{2}\right)$, bands can only take place when these modes have a significant $\alpha_{z z}$ component, in either a side-on or an end-on orientation of the ring. The $p$-nitro group $\nu_{\mathrm{s}}\left(\mathrm{NO}_{2}\right)$ band was observed intensely at $1330 \mathrm{~cm}^{-1}$ at high concentrations. This is taken as support for the folded-over structure of DNP amino acids under these conditions. In the intermediate concentration range of $1-10 \mu \mathrm{M}$ the 0 nitro group $\nu_{\mathrm{s}}\left(\mathrm{NO}_{2}\right)$ band at $1271 \mathrm{~cm}^{-1}$ generally occurred more intensely. This serves as evidence for the extended structure II in which the DNP ring takes on a side-on orientation. Other in-plane modes of the DNP ring represented by bands at 1612 and $1583 \mathrm{~cm}^{-1}\left(\mathrm{e}_{2 \mathrm{~g}}\right.$ modes of the phenyl group) are intensified at the same time. At low concentrations both $\nu_{\mathrm{s}}\left(\mathrm{NO}_{2}\right)$ bands are usually very weak, suggesting that the DNP ring lies almost flat on the sur- face. Also, the $833-\mathrm{cm}^{-1}$ symmetrical ring-breathing mode shows very little or no intensity in its SERS band. On the other hand, a series of otherwise weak SERS bands at 1147, $1056,928,890,781,684,589,490$, and $370 \mathrm{~cm}^{-1}$ have increased considerably in relative intensity. We associate these bands with out-of-plane modes of the two nitro groups $\left(\mathrm{NO}_{2}\right.$ twist, rock, wag) and the phenyl ring.

Similar arguments for at least two distinct orientations of DANS-Asp on silver can be made. The additional lower frequency SERS band at $782 \mathrm{~cm}^{-1}$ is associated in an analogous way with a ring-breathing motion that contains a substantial out-of-plane polarizability component, $\alpha_{z z}$, such that it becomes SERS-active when the planar ring is orientated flat on the surface. However, a large population of DANS-Asp molecules with the ring system orientated in a side-on or end-on fashion is also indicated by the presence of intense in-plane modes at 1371 and 1575 $\mathrm{cm}^{-1}$.

Acknowledgment. This work was supported by Army Research Office Grant DAAG29-85-K-0102 and by NIH Grant GM-30904. We thank Dr. Lee Guterman for the fluorescence emission measurements and Professor J. A. Koningstein and Dr. L. Haley of Carleton University for their advice on the pulsed Raman measurements.

Registry No. DNP-Met, 3950-28-5; PNP-Cys, 35749-09-8; DNP-Asp, 7683-81-0; $\alpha$-DNP-Lys, 24696-20-6; DANS-Asp, 1100-24-9; Met, 63-68-3; Cys, 56-89-3; Asp, 56-84-8; Lys, 56-87-1; Ag, 7440-22-4.

\title{
Correlation between SERS of Pyridine and Electrochemical Response of Silver Electrodes in Halide-Free Alkaline Solutions
}

\author{
M. L. A. Temperini and D. Sala \\ Instituto de Quimica de Universidade de São Paulo, CP 20780, São Paulo, Brazil \\ G. I. Lacconi, A. S. Gioda, and V. A. Macagno \\ INFIQC, Depto. de Fisicoquimica, Fac. de Ciencias Quimicas, Universidad Nacional de \\ Cördoba, Sucursal 16, casilla de correo 61, (5016) Córdoba, Argentina \\ A. J. Arvia* \\ Instituto de Investigaciones Fisicoquimicas Teóricas y Aplicadas (INIFTA), Sucursal 4, casilla \\ de correo 16, (1900) La Plata, Argentina \\ Received July 13, 1987. In Final Form: February 25, 1988
}

\begin{abstract}
Surface-enhanced Raman scattering (SERS) of pyridine (Py) on Ag electrodes in alkaline solutions free of halide ions was obtained at $25^{\circ} \mathrm{C}$ as a function of the applied potential. The Ag surface was activated for SERS through repetitive oxidation-reduction cycles (ORC), the effect being dependent on the electrochemical electrode history. The SERS effect was correlated to the activation for the hydrogen evolution reaction (HER), which can be obtained by means of potentiodynamic as well as potentiostatic procedures. The maximum SERS activity was achieved at potentials near the potential of zero charge (pzc) of polycrystalline Ag and appeared to be related to the maximum observed in the roughness factor vs potential curve. These results can be interpreted through the formation of a new uniform globular overlayer structure on the electroreduced $\mathrm{Ag}$ surface, which apparently exhibits a certain degree of preferred crystallographic orientation. Three well-defined potential regions can be distinguished for the complex competitive interactions between $\mathrm{H}_{2} \mathrm{O}, \mathrm{OH}^{-}$ion, and $\mathrm{Py}$ with the new $\mathrm{Ag}$ electrode surface.
\end{abstract}

\section{Introduction}

Surface-enhanced Raman scattering is recognized as a very powerful and sensitive method for characterizing and investigating structural aspects of adsorbates at electrode surfaces ${ }^{1,2}$ and for learning more about the structure of the electrical double layer.
Since the discovery of SERS, ${ }^{3,4}$ a large number of works have focused the attention to SERS of Py on Ag electrodes

(1) Surface Enhanced Raman Scattering, Chang, R. K., Furtak, T. E., Eds.; Plenum: New York, 1982

(2) Seki, H. J. Electron Spectrosc. Relat. Phenom. 1986, 39, 289. 
in aqueous solutions containing mainly an alkaline chloride, principally $\mathrm{KCl}^{3-10}$ SERS from electrogenerated halogen and trihalide ions coadsorbed on $\mathrm{Pt}$ has also been demonstrated, ${ }^{7-9}$ The presence of halide ions has been considered of primary importance for the $\mathrm{Ag}$ electrode activation through the empirical oxidation-reduction potential cycling (ORC) despite the fact that practically little SERS investigation is reported for solutions containing free halide. At present the structure of the activated $\mathrm{Ag}$ electrode surface, which is useful for SERS, is not completely understood, although it must be considered of major relevance for approaching the proper theory of SERS. The SEM micrographs of SERS-active Ag surfaces $^{11}$ are similar to those SEM micrographs recently described for electrodispersed $\mathrm{Pt}$ and Au electrodes. ${ }^{12,13}$ For the latter, the STM (scanning tunneling microscope) images show details at the nanometer scale which correspond to a large ensemble of metal clusters of an average diameter of about $10 \mathrm{~nm}$. Such an arrangement probably implies for each metal supercluster a new kind of structure not found in smooth metals. ${ }^{14-16}$ This reflects, for instance, in the new bands of the electroreflectance spectra of these metal surfaces with respect to those of smooth polycrystalline electrode surfaces. For these electrodispersed metal surfaces including that consisting of $\mathrm{Ag}$ spheres of small radius $(\approx 5 \mathrm{~nm})$ one can expect a specific contribution of surface plasmon excitation supplying the SERS with adsorbed molecules. ${ }^{15}$

Recently it has been reported that ORC of the same kind as those used for SERS activation on Ag electrodes also promote an enhancement of the hydrogen evolution reaction in halide-free alkaline solutions. ${ }^{17}$ This effect appears to be related to a change in both the electrode roughness and the distribution of active $\mathrm{Ag}$ sites. Therefore, it is interesting to attempt to establish some type of correlation between SERS and HER enhancement.

The present paper is devoted to the investigation of SERS of Py on Ag electrodes, principally with regard to the following aspects: (i) SERS of Py on Ag in halide-free alkaline solution, (ii) controlled $\mathrm{Ag}$ activation for SERS through ORC covering a potential window that can be thermodynamically defined, and (iii) SERS and HER activation effects on $\mathrm{Ag}$.

(3) Fleischmann, M.; Hendra, P. J.; Mc Quillan, A. J. Chem. Phys. Lett. 1974, 26, 163.

(4) Jeanmaire, D. L.; Van Duyne, R. P. J. Electroanal. Chem. 1977 , 84,1 .

(5) Owen, J. F.; Chen, T. T.; Chang, R. K.; Laube, B. L. J. Electroanal. Chem. 1983, 150, 389.

(6) Pettinger, B.; Moerl, L. J. Electroanal. Chem. 1983, 150, 415.

(7) Loo, B. H. Solid State Commun. 1982, 43, 349.

(8) Loo, B. H. J. Phys. Chem. 1983, 87, 3003.

(9) Loo, B. H.; Lee, Y. G. J. Phys. Chem. 1984, 88, 706.

(10) Cross, N. A.; Pemberton, J. E. J. Electroanal. Chem. 1987, 217, 93. 79.

(11) Pemberton, J. E.; Girand, M. M. J. Electroanal. Chem. 1987, 217 ,

(12) Vázquez, L.; Gớmez, J.; Baró, A. M.; Garcia, N.; Gonzälez-Velasco, J.; Vara, J. M.; Arvia, A. J. J. Am. Chem. Soc. 1987, 109, 1730.

(13) Gómez, J.; Vaźquez, L.; Barô, A. M.; Alonso, C.; Gonzâlez, E.; Gonzalez Velasao, J.; Arvia, A. J. J. Electroanal. Chem. 1988, 240, 77.

(14) Rowlinson, J. S. J. Chem. Soc., Faraday Trans. 2 1986, 82, 180 (Faraday Symp. 20)

(15) Pettinger, B.; Tadjeddine, A.; Kolb, D. M. Chem. Phys. Lett. $1979,66,544$. 1777 .

(16) Wang, J. S.; Kerker, M. Phys. Rev. B: Condens. Mattr 1981, 24,

(17) Lacconi, G. I.; Gioda, A. S.; Macagno, V. A. Electrochim. Acta $1985,30,211$.

\section{Experimental Section}

The working electrodes were made from Ag Koch-Light $99.999 \%$, the design and the exposed surface to the solution being dependent on the type of experiment. In potentiodynamic as well as in potentiostatic electrochemical experiments the working electrodes were made of a 7-mm-diameter $\mathrm{Ag}$ rod embedded in Teflon with either an elliptical surface of $0.50 \mathrm{~cm}^{2}$ or a disk of $0.33 \mathrm{~cm}^{2}$ geometrical area. For spectroelectrochemical measurements the electrodes were made from a Ag disk cut from a $3-\mathrm{mm}$ rod embedded in polyester resin $\left(0.07 \mathrm{~cm}^{2}\right)$. The electrodes were polished with cerium oxide prior to each experiment.

Solutions were prepared from reagent grade $\mathrm{NaOH}$, and water was purified through a Millipore-Milli-Q system. In spectroelectrochemical experiments the solutions were also $0.05 \mathrm{M}$ in $\mathrm{Py}$. The electrolyte solutions were deaerated by $\mathrm{N}_{2}$ bubbling.

The measurements were performed in a conventional electrolysis cell. For the Raman or SERS spectra a small glass rectangular Raman cell of $10 \mathrm{~cm}^{3}$ was used. The counter electrode was a large area $\mathrm{Pt}$ sheet, and the reference electrode consisted of $\mathrm{Hg} / \mathrm{HgO} / 0.1 \mathrm{M} \mathrm{NaOH}$.

Procedure for Ag Electrode Activation. Ag electrodes for the HER were activated through the application of ORC by using repetitive triangular potential sweeps between the potential of the HER and the potential of the anodic Ag(II) oxide layer formation, following the previously reported procedure. ${ }^{17}$

SERS Spectra. SERS spectra were obtained with a Jarrell-Ash 25-300 double-monochromator spectrograph fitted with a photomultiplier tube detector (ITT-FW 130). The excitation radiation was $514.5 \mathrm{~nm}$ (Spectra Physics Ar laser model 165) with $40 \mathrm{~mW}$ of power. The spectral resolution in all measurements was $10 \mathrm{~cm}^{-1}$. Further details of the procedure have been reported elsewhere. ${ }^{18}$

The spectroelectrochemical measurements were obtained by cycling the Ag electrode between preset oxidation $\left(E_{\mathrm{s}, \mathrm{a}}\right)$ and reduction potentials $\left(E_{\mathrm{B}, \mathrm{c}}\right)$ followed by recording the SERS spectra of Py at different potential holding values, $E_{\mathrm{h}}$.

Raman Spectroscopy of the Ag Surface. Raman spectra of the Ag surface were obtained with the experimental setup already described for SERS. By means of Raman spectroscopy it is possible to characterize the electroformed species at the $\mathrm{Ag} /$ electrolyte solution interphase when different electrochemical treatments are applied. Nevertheless, this analysis is rather complex since the processes occurring at the electrode are photoelectrochemical in nature and, as a consequence, are strongly dependent on parameters such as electrode potentials, type of electrochemical treatment, energy and power of the excitation radiation, time of surface illumination, etc.

Complementary Electrochemical Measurements. Ag activation for the HER can also be achieved through a potentiostatic electrochemical treatment, as has been recently described. ${ }^{19}$ Runs were performed by using a rotating Ag disk electrode $\left(0.33 \mathrm{~cm}^{2}\right)$, which was held at the potential $E_{\mathrm{h}}\left(-1.45 \mathrm{~V}<E_{\mathrm{h}}<0.45 \mathrm{~V}\right)$ during $10 \mathrm{~min}$ while it was rotated at $550 \mathrm{rpm}$. The comparison of $E / j$ potentiodynamic profiles run before and after the potential holding was taken as a measure of the HER enhancement. Simultaneously, the roughness factor $(r)$ of the Ag electrodes as a function of the applied potential $E_{\mathrm{h}}$ was measured through the $\mathrm{Pb}^{2+}$ underpotential deposition (upd) charge. Nevertheless, this dependence of $r$ on $E_{\mathrm{h}}$ should be handled cautiously since the values of $r$ might include some restructuring effects at the Ag surface due to the cycles of upd and stripping of lead themselves. ${ }^{20-22}$ In this context the values of $r$ reported in this work should be considered only as the lowest limiting values.

Scanning Electron Microscopy (SEM). SEM micrographs of $\mathrm{Ag}$ electrodes after potentiodynamic activation cycles between preset anodic and cathodic switching potentials were obtained by using a Philips SEM Model 507 B.

(18) Temperini, M. L. A.; Lacconi, G. I.; Sala, O. J. Electroanal. Chem. $1987,227,21$

(19) Villullas, H. M.; Lacconi, G. I.; Gioda, A. S.; Macagno, V. A. Electrochim. Acta, in press.

(20) Guy, A. L.; Pemberton, J. E. Langmuir 1985, 1, 518.

(21) Pemberton, J. E.; Coria-Garcia, J. C.; Hoff, R. L. Langmuir 1987, 3,150 .

(22) Guy, A. L.; Berganii, B.; Pemberton, J. E. Surf. Sci. 1985, 150, 226. 


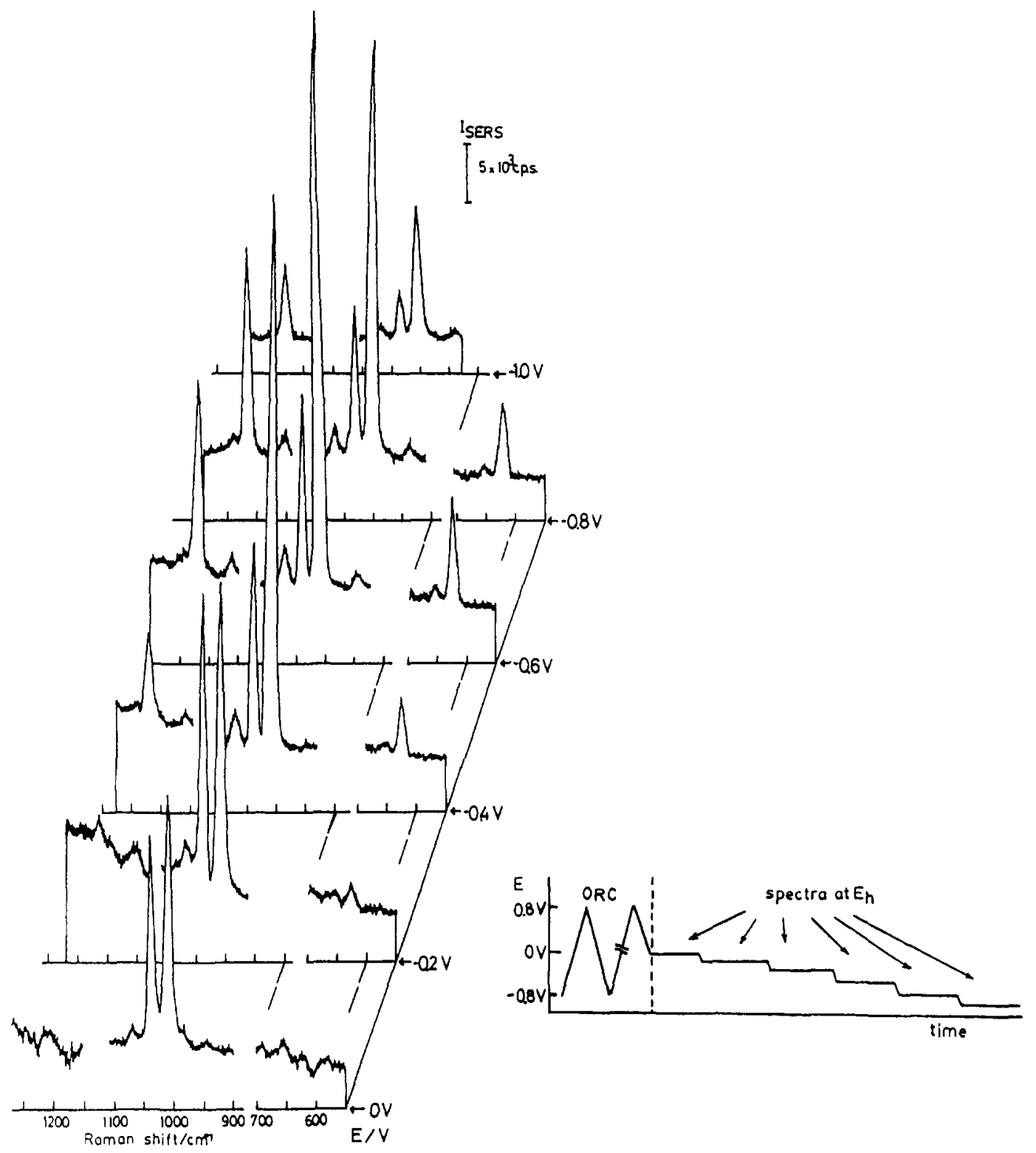

Figure 1. Potential dependence of SERS intensity in 0.1 M NaOH $+0.05 \mathrm{M}$ Py solution. Spectra were recorded at different potential holding values, $E_{\mathrm{h}}$, after $\mathrm{Ag}$ electrode activation by $\mathrm{ORC}$ at $0.1 \mathrm{~V} \mathrm{~s}^{-1}$.

\section{Results}

SERS Measurements. The Raman spectrum of Py on activated $\mathrm{Ag}$ electrodes in alkaline solutions free of halide ions exhibits an intensity enhancement of the order of $10^{4}-10^{5}$ times the Raman intensity of Py in solution. This result is 1-2 orders of magnitude lower than the maximum SERS effect observed for the same system in halide-containing solutions.

1. Influence of Ag Electrode History and Applied Potential. The SERS spectrum of Py in a $0.1 \mathrm{M} \mathrm{NaOH}$ solution strongly depends on the potential at which it was recorded. The spectra depicted in Figure 1 were obtained after the Ag electrode was activated through the perturbing potential scheme included in the figure.

In the $500-1300-\mathrm{cm}^{-1}$ frequency range for the spectra recorded stepwise between 0 and $-1.0 \mathrm{~V}$, a set of bands related to the different vibrational modes of Py interacting with the $\mathrm{Ag}$ surface are observed (Table I). The band assignment was made with previously reported results ${ }^{23,24}$ taken into account. The dependence of the SERS intensity

(23) Kim, M.; Itoh, K. J. Electroanal. Chem. 1985, 188, 137.

(24) Creighton, J. A. Surf. Sci. 1983, 124, 209
Table I. Assignments of SERS Band Maxima of Py Read at Different Applied Potential to an Ag Electrode in $0.1 \mathrm{M}$ $\mathrm{NaOH}+0.05 \mathrm{MPy}$

\begin{tabular}{|c|c|c|c|c|c|c|}
\hline \multicolumn{6}{|c|}{ Raman shift $\left(\mathrm{cm}^{-1}\right)$ at $E(V)$} & \multirow[b]{2}{*}{ assignments $[23,24]$} \\
\hline 0 & -0.2 & -0.4 & -0.6 & -0.8 & -1.0 & \\
\hline 625 & 625 & 625 & 624 & 622 & & ation \\
\hline 658 & 658 & 655 & 654 & 653 & & \\
\hline 1008 & 1008 & 1009 & 1008 & 1007 & 1005 & ring \\
\hline 1038 & 1038 & 1035 & 1036 & 1033 & 1032 & \\
\hline 1068 & $\begin{array}{l}1069 \\
1155\end{array}$ & $\begin{array}{l}1068 \\
1152\end{array}$ & $\begin{array}{l}1068 \\
1152\end{array}$ & $\begin{array}{l}1066 \\
1150\end{array}$ & $\begin{array}{l}1066 \\
1150\end{array}$ & erormatio \\
\hline 210 & 12 & 1217 & 1216 & 2 & & hil \\
\hline
\end{tabular}

bands with the applied potential is shown in Figure 2. For every one of the main vibrational modes the potential dependence is different. Thus, for the band at $1008 \mathrm{~cm}^{-1}$ SERS intensity changes with the potential according to an asymmetrical bell-shaped curve with a maximum at ca. $-0.5 \mathrm{~V}$ and a shoulder at ca. $0 \mathrm{~V}$, whereas for the band at $1038 \mathrm{~cm}^{-1}$ the intensity shows a maximum at approximately $-0.2 \mathrm{~V}$ and a hump at ca. $-0.5 \mathrm{~V}$. Likewise, the band at $1250 \mathrm{~cm}^{-1}$ has a maximum at ca. $-0.75 \mathrm{~V}$ and the band at $625 \mathrm{~cm}^{-1}$ a maximum at ca. $-0.6 \mathrm{~V}$. The band at $3060 \mathrm{~cm}^{-1}$ (not shown in Figure 1) is rather broad, but 


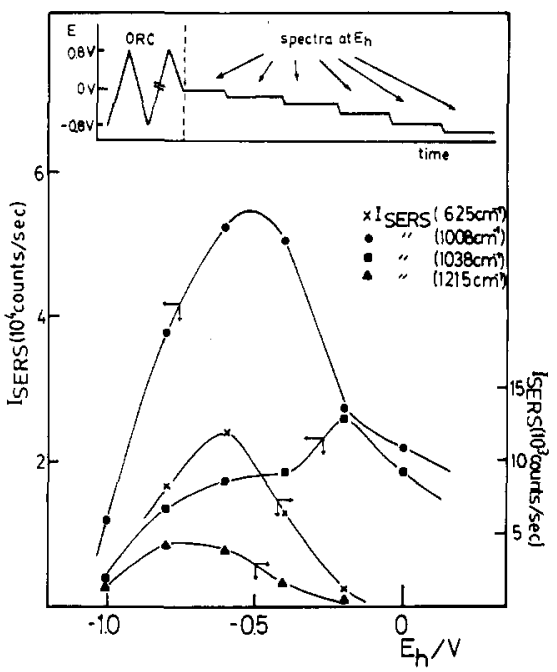

Figure 2. SERS intensity potential dependence of different vibrational bands of $P y$.

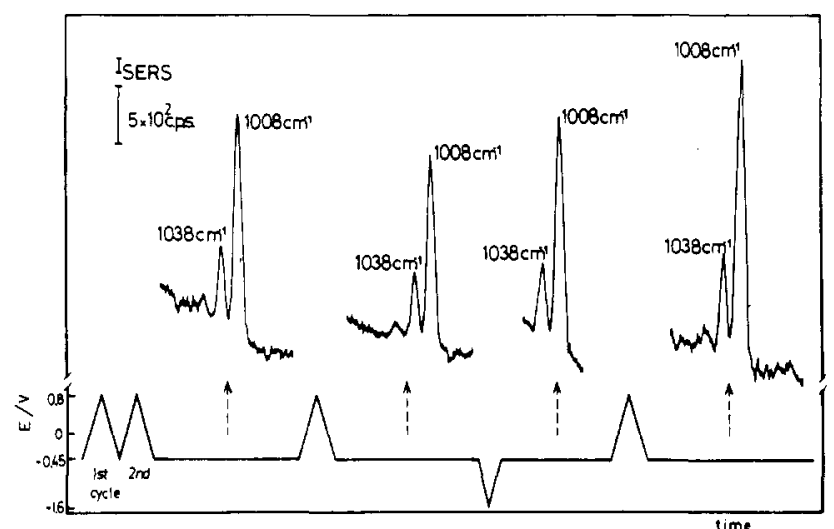

Figure 3. Influence of the electrochemical history of the Ag surface on $I_{\text {SERS }}$ for the bands corresponding to the ring-breathing vibrational modes of $\mathrm{Py}$.

according to previously reported results ${ }^{5}$ it modifies with the potential practically in the same way as the narrower bands which appear at lower frequencies.

The dependence of SERS intensity $\left(I_{\text {SERS }}\right)$ of the principal bands ( 1008 and $1038 \mathrm{~cm}^{-1}$ ) with the electrochemical history of the $\mathrm{Ag}$ electrode surface, that is, the number of $\mathrm{ORC}$, anodic and cathodic switching potentials, etc., is illustrated in Figure 3 . The $I_{\text {SERS }}$ at $1008 \mathrm{~cm}^{-1}$, which shows a tendency to diminish between the second and the third cycle, recovers the original intensity just after a potential sweep in the negative direction up to $-1.6 \mathrm{~V}$. On the other hand, an anodic scan up to ca. $0.8 \mathrm{~V}$ (oxide electroformation potential region) yields a noticeable increase of $I_{\mathrm{SERS}}$ measured at $-0.45 \mathrm{~V}$.

The influence of the applied potential on $I_{\mathrm{SERS}}$ for the $1008-\mathrm{cm}^{-1}$ band was also investigated by using a linear potential scanning and recording simultaneously both the $E / j$ and the $E / I_{\text {SERS }}$ profiles. These results are shown in Figure 4 after the appropriate base-line correction. Again, the maximum of $I_{\mathrm{SERS}}$ appears at ca. $-0.5 \mathrm{~V}$. Nevertheless, during the positive potential going sweep the $E / I_{\mathrm{SERS}}$ curve is drastically depressed, although still apparently showing a maximum at ca. $-0.4 \mathrm{~V}$ and a shoulder at ca. $0.1 \mathrm{~V}$. The same behavior is observed in general during a potential cycling, though in this case the $I_{\text {SERS }}$ values show a trend to increase slightly during the first ORC and then to decrease slowly on the subsequent cycles.

2. Influence of $\boldsymbol{E}_{\mathrm{g}, \mathrm{a}}$. The $I_{\mathrm{SERS}}$ for the band at 1008 $\mathrm{cm}^{-1}$ always read at $-0.8 \mathrm{~V}$ changes during the $\mathrm{ORC}$, where

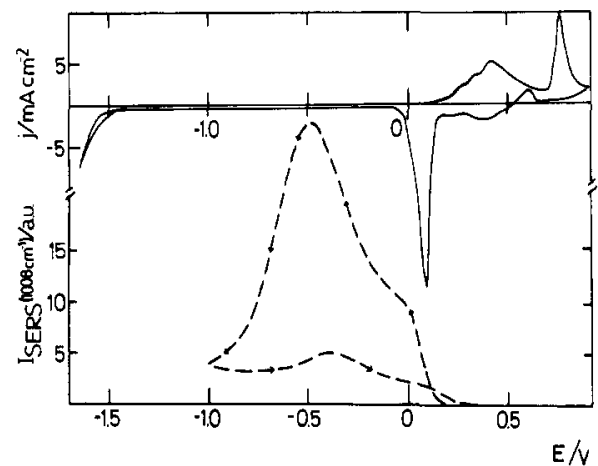

Figure 4. Simultaneous recording of $E / j$ and $E / I_{\text {SERS }}\left(1008 \mathrm{~cm}^{-1}\right)$ profiles in $0.1 \mathrm{M} \mathrm{NaOH}+0.05 \mathrm{M}$ Py solution at $0.01 \mathrm{~V} \mathrm{~s}^{-1}$.

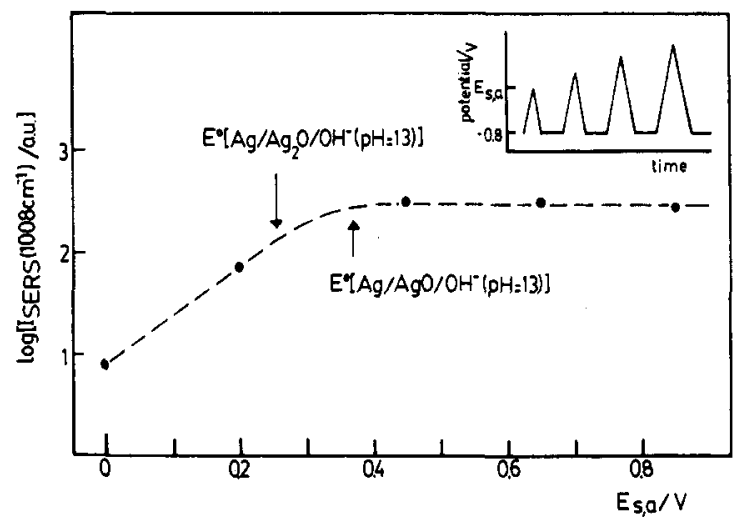

Figure 5. Dependence of the $1008-\mathrm{cm}^{-1}$ band read at $-0.8 \mathrm{~V}$ on $E_{\mathrm{s}, \mathrm{a}}$, the latter being changed stepwise during ORC.

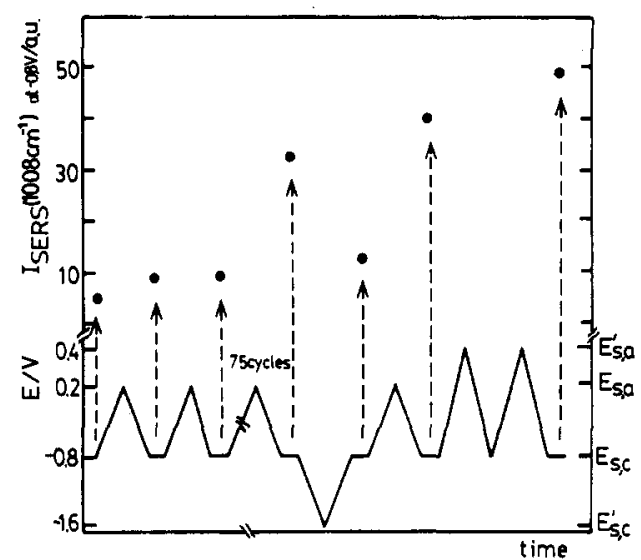

Figure 6. Influence of the switching potential values $\left(E_{\mathrm{s}, \mathrm{c}}, E_{\mathrm{s}, \mathrm{c}}^{\prime}\right.$ $E_{\mathrm{s}, \mathrm{a}}$, and $E_{\mathrm{s}, \mathrm{g}}^{\prime}$ ) on $I_{\mathrm{SERS}}$ for the $1008-\mathrm{cm}^{-1}$ band read at $-0.8 \mathrm{~V}$ in a highly activated $\mathrm{Ag}$ electrode (75 ORC).

for each cycle $E_{8,8}$ is changed stepwise from 0 to $0.85 \mathrm{~V}$ (Figure 5) for $E_{\mathrm{s}, \mathrm{c}}=-0.8 \mathrm{~V}$ and $v=0.1 \mathrm{~V} \mathrm{~s}^{-1}$, the ORC being performed in the absence of illumination. For the ring-breathing vibrational mode $\left(1008 \mathrm{~cm}^{-1}\right)$ the $\log I_{\text {SERS }}$ vs $E_{\mathrm{s}, \mathrm{a}}$ plot exhibits a linear region comprised between 0 $\mathrm{V}$ and the threshold potential for silver(I) oxide formation; otherwise, when the threshold potential for the formation of $\mathrm{Ag}$ (II) species is exceeded, $I_{\mathrm{SERS}}$ reaches a limiting value. Apparently, the electroreduction of the Ag(II) oxide layer, that is, the oxide formed at $E_{\mathrm{s}, \mathrm{a}}>0.36 \mathrm{~V}$, does not contribute to an increase in the Ag electrode activation for SERS. On the other hand, for a constant $E_{\text {s a }}$ set within the region where SERS intensity increases, it can be observed that $I_{\mathrm{SERS}}$ rises approximately linearly with the number of ORC. Furthermore, when a Ag electrode previously activated for SERS at $0.2 \mathrm{~V}$ is scanned up to -1.6 V (Figure 6), it shows an appreciable increase in the HER 


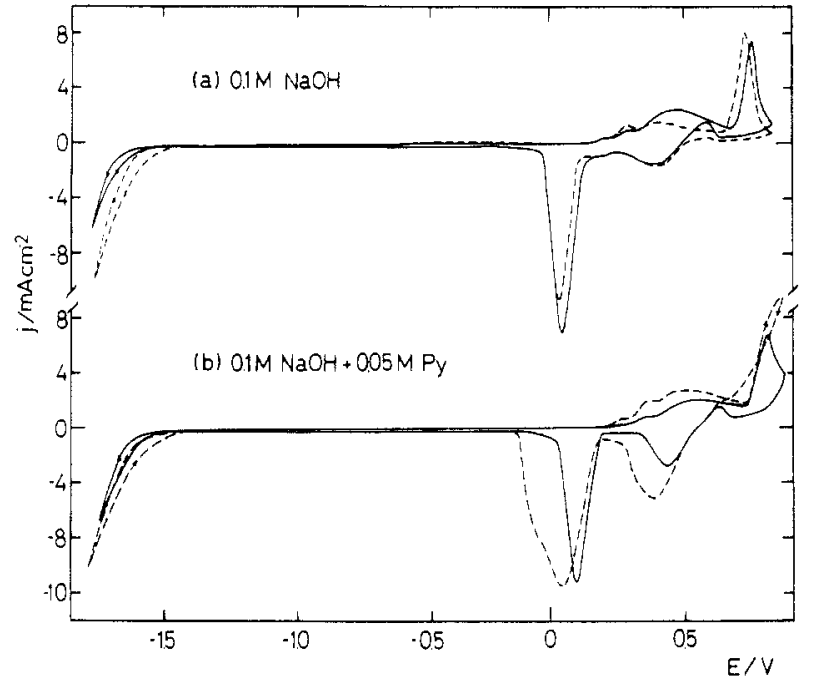

Figure 7. Voltammograms run at $0.1 \mathrm{~V} \mathrm{~s}^{-1}$. First (-) and twentieth (..-) voltammetric profiles are depicted: (a) $0.1 \mathrm{M}$ $\mathrm{NaOH}$; (b) $0.1 \mathrm{M} \mathrm{NaOH}+0.05 \mathrm{M}$ Py.

current, but the subsequent $I_{\text {SERS }}$ measurement of the $1008-\mathrm{cm}^{-1}$ band at $-0.8 \mathrm{~V}$ clearly decreases to a value that is about one-third of the initial one, probably due to loss of atomic scale roughness. However, the following anodic potential scan up to $0.2 \mathrm{~V}$ results in an abrupt recovery

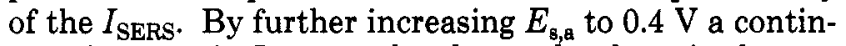
uous increase in $I_{\text {SERS }}$ can be observed at least in the two subsequent potential scans. It is interesting to notice that the potential limit of $0.4 \mathrm{~V}$ is within the region of $E_{\mathrm{s}, \mathrm{a}}$ where $I_{\text {SERS }}$ attains a limiting value as in Figure 5.

3. Influence of the Formation of Silver Oxides. When a $\mathrm{Ag}$ electrode which has achieved the maximal SERS activation as it is followed through the $1008-\mathrm{cm}^{-1}$ band at $-0.45 \mathrm{~V}$ is subjected to an anodic potential scan to $0.34 \mathrm{~V}$, the resulting potential spectrum recorded at this potential is similar to the spectrum of $\mathrm{Ag}$ (II) silver oxide reported in the literature, ${ }^{18,25}$ with a band at $430 \mathrm{~cm}^{-1}$ which has been assigned to the stretching vibrational mode of the Ag-O band. The intensity of this band is practically independent of $E_{\mathrm{s}, \mathrm{a}}$ up to $E_{\mathrm{s}, \mathrm{a}}=0.68 \mathrm{~V}$, although the overall spectrum depends on the electrode history. ${ }^{18}$ The origin of the $430-\mathrm{cm}^{-1}$ band has been assigned to the photoelectrochemical formation of AgO. ${ }^{18}$ It should be mentioned that at the potential values of $\mathrm{AgO}$ formation, that is, for $E_{\mathrm{s}, \mathrm{a}}$ values lower than $0.68 \mathrm{~V}$, SERS of Py is not observed, this being an indication that the presence of Py in solution has no primary influence on the $\mathrm{Ag}$ (II) oxide formation.

Electrochemical Results. The voltammograms of Ag in the base electrolyte and in the electrolyte containing Py were recorded under comparable conditions to see any possible influence of Py on the anodic formation and cathodic electroreduction of the complex oxide layers.

The characteristics of the Ag voltammograms in plain electrolyte are remarkably sensitive to the history of ORC (Figure 7a). The most dramatic voltammetric changes are seen in the HER region. The current associated with this process increases continously according to the number of ORC run between ca. -1.7 and $0.9 \mathrm{~V}$ at $v=0.1 \mathrm{~V} \mathrm{~s}^{-1}$. Additional changes resulting from ORC can also be noticed in the potential range of oxide layer electroformation/ electroreduction. Although the height of the different current peaks observed in the oxide region remains practically constant during 30-min ORC, for longer times the voltammetric change associated with those processes also

(25) Kotz, R.; Yeager, E. J. Electroanal. Chem. 1980, 111, 105.

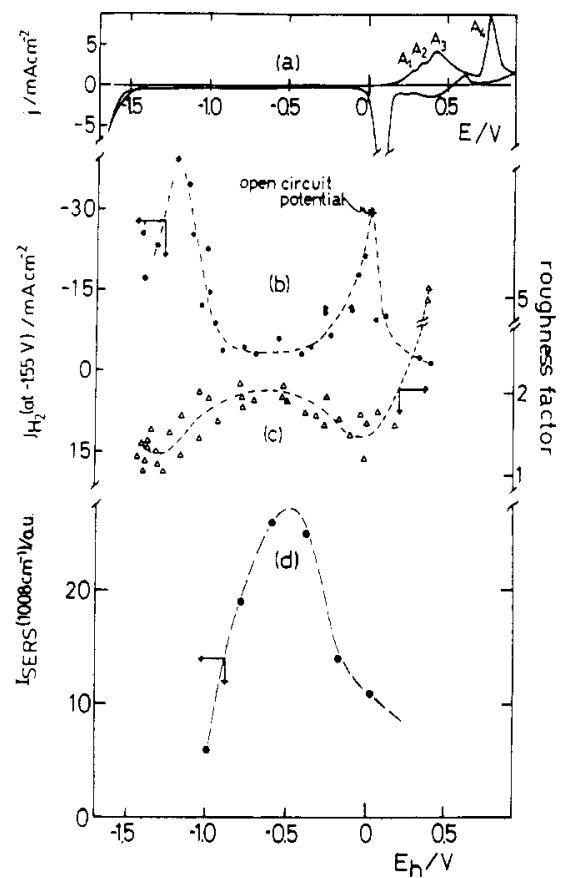

Figure 8. Dependences of the HER enhancement (curve b), roughness factor (curve c), and $I_{\text {SERS }}$ of Py $\left(1008-\mathrm{cm}^{-1}\right.$ band) (curve d) on $E_{\mathrm{h}}: 0.1 \mathrm{M} \mathrm{NaOH}+0.05 \mathrm{M} \mathrm{Py}$. Ag electrode activation for the HER was achieved by holding the potential at $E_{\mathrm{h}}$ with the working electrode under rotation at $550 \mathrm{rpm}$. The $E / j$ profile of $\mathrm{Ag}$ in $0.1 \mathrm{M} \mathrm{NaOH}$ is also shown for the sake of comparison (curve a).

begins to increase progressively. ${ }^{17}$

Comparable voltammograms run in the presence of 0.05 M Py (Figure 7b) show that the activation of HER in this case is slightly less than in plain $0.1 \mathrm{M} \mathrm{NaOH}$. Anodic voltammetric peaks related to $\mathrm{Ag}(\mathrm{I})$ and $\mathrm{Ag}(\mathrm{II})$ oxide electroformation remain practically the same in the presence of $\mathrm{Py}$, but in contrast, the voltammetric electroreduction charge increases on potential cycling and shifts more negatively, particularly the charge related to $\mathrm{Ag}(\mathrm{II})$ silver oxide.

The activation for HER on silver in base solutions can also be produced (Figure 8 ) by holding the potential at a fixed value $\left(E_{\mathrm{h}}\right)$ for a certain time. ${ }^{19}$ Under these conditions the electrode roughness factor exhibits a peculiar dependence on $E_{\mathrm{h}}$, as shown in Figure 8c. This curve shows a maximum value of $r$ at ca. $-0.5 \mathrm{~V}$ within the $0 \mathrm{~V}$ $>E_{\mathrm{h}}>-1.4 \mathrm{~V}$ range. For $E_{\mathrm{h}}$ values greater than $0 \mathrm{~V}, r$ increases continuously with $E_{\mathrm{h}}$ due to silver oxide formation.

The dependence of $I_{\mathrm{SERS}}$ on $E_{\mathrm{h}}$ as followed through the $1008-\mathrm{cm}^{-1}$ band also exhibits a maximum at about $-0.5 \mathrm{~V}$ (Figure $8 \mathrm{~d}$ ). At this potential, one admits that no oxide layer exists on the Ag surface (Figure 8a). On the other hand, the HER current read at $-1.55 \mathrm{~V}$ for an Ag electrode after activation at a constant $E_{\mathrm{h}}$ depends on the latter in a rather complex way (Figure $8 \mathrm{~b}$ ). The $j_{\mathrm{H}_{2}}$ vs $E_{\mathrm{h}}$ plot exhibits two maxima, one at about -1.2 and another one at $0 \mathrm{~V}$, and a minimum at nearly $-0.5 \mathrm{~V}$. The U-shaped $j_{\mathrm{H}_{2}}$ vs $E_{\mathrm{h}}$ relationship is interpreted on the one hand at potentials greater than $0 \mathrm{~V}$ by the formation of silver oxide layers and on the other at potentials lower than $-1.2 \mathrm{~V}$ by the formation of hydrogen bubbles. ${ }^{19}$ The maximum rate for the HER appears at two well-defined potentials, namely, $E_{\mathrm{h}}=0 \mathrm{~V}$ and $E_{\mathrm{h}}=-1.2 \mathrm{~V}$. The values of $r$ also exhibit a complex dependence on $E_{\mathrm{h}}$, which reflects in the appearance of a maximum value of $r$ at $E_{\mathrm{h}}=-0.5 \mathrm{~V}$ and an abrupt increase for $E_{\mathrm{h}}>0 \mathrm{~V}$, that is, when $E_{\mathrm{h}}$ is set in the potential range where silver oxide can be formed. 


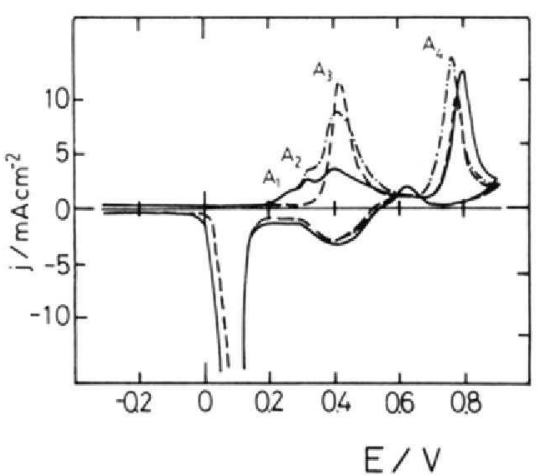

Figure 9. Voltammograms run in the oxide electroformation/ electroreduction region, $0.1 \mathrm{M} \mathrm{NaOH}, 0.1 \mathrm{~V} \mathrm{~s}^{-1}$. (-) stabilized profile after ORC without previous potential holding; (-..) first and $(-\cdot)$ second cycles after potential holding at $E_{\mathrm{h}}=-1.45 \mathrm{~V}$ and stirring at $550 \mathrm{rpm}$.

From the comparison of parts a-d of Figure 8, the following conclusions can be derived: (i) the minimum SERS intensity at $1008 \mathrm{~cm}^{-1}$, the minimum activation for the HER, and the maximum value of $r$ are observed between 0 and $-1.0 \mathrm{~V}$. (ii) The greatest SERS intensity at $1008 \mathrm{~cm}^{-1}$ is noticed when the applied potential moves from the positive to the negative side, that is, as the anodic layer becomes progressively removed from the electrode surface. The anodic layer no longer exists when the applied potential is lower than the open circuit potential. (iii) SERS intensity begins to decrease, and oppositely, the HER current starts to increase when the applied potential becomes lower than $-0.5 \mathrm{~V}$. (iv) Under voltammetric sweep conditions, once the SERS intensity has diminished it remains unaltered on the subsequent positive potential going scan (Figure 4).

Furthermore, it should be noticed that the potentiostatic activation of the $\mathrm{Ag}$ electrode also brings out, together with the increase in the HER current, electrode surface modifications which reflect in the voltammetric formation of the $\mathrm{Ag}(\mathrm{I})$ oxide layer. Then, the resulting voltammogram (Figure 9) is similar to that recently reported for $\mathrm{Ag}$ electrodes in alkaline solutions that were kept at open circuit during a relatively long period of time. ${ }^{26}$ The first voltammogram run in the positive potential direction of Ag electrodes activated at $E_{\mathrm{h}}=-1.45 \mathrm{~V}$ (Figure 9) exhibits no $A_{1}$ and $A_{2}$ peaks, an apparent slight increase in the charge of peak $\mathrm{A}_{3}$, and a net decrease in the charge of peak $\mathrm{A}_{4}$. Subsequent potential cycling returns the voltammogram to the already known stabilized voltammogram of an untreated Ag electrode.

\section{Discussion}

The present results offer the possibility of considering some basic aspects of SERS, particularly concerning the characteristics of activated $\mathrm{Ag}$ electrodes and others related to SERS of Py itself.

Characteristics of Ag Electrodes. The activation of Ag electrodes in alkaline solution in the absence of halide ions can be successfully accomplished when the potential limit of the ORC lies between the equilibrium potential of the reaction

$$
\mathrm{Ag}+\mathrm{OH}^{-} \rightleftarrows \mathrm{Ag}(\mathrm{OH})_{\text {ad }}+\mathrm{e}^{-}
$$

whose value $E_{r, 1}^{\circ} \approx 0.0 \mathrm{~V}$ has been estimated from the

(26) Hepel, M.; Tomkiewicz, M. J. Electrochem. Soc. 1984, 131, 1288. (27) Standard Potentials in Aqueous Solutions; Bard, A. J., Parsons, R., Jordan, J., Eds.; Marcel Dekker: New York, 1985; p 310.

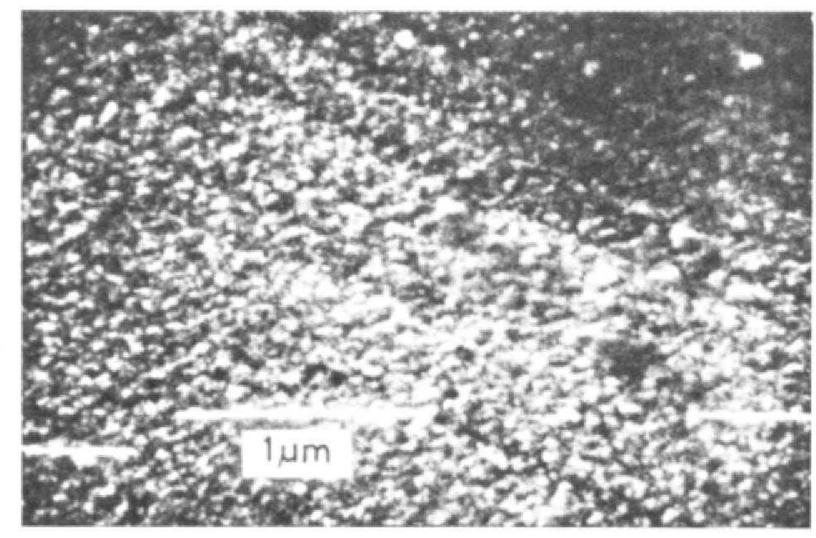

Figure 10. Scanning electron micrograph. Ag surface activated through $20 \mathrm{ORC}$ at $0.1 \mathrm{~V} \mathrm{~s}^{-1}$ in the -1.6 to $0.9 \mathrm{~V}$ range.

open circuit potential and voltammetry at low $v$ and the potential value related to the $\mathrm{Ag}(\mathrm{II})$ oxide $/ \mathrm{Ag}$ couple

$$
\mathrm{AgO}+2 \mathrm{H}^{+}+2 \mathrm{e}^{-} \rightleftharpoons \mathrm{Ag}+\mathrm{H}_{2} \mathrm{O}
$$

which is $E_{r, 2}^{\circ}=0.36 \mathrm{~V}\left(\mathrm{vs} \mathrm{Hg} / \mathrm{HgO} / \mathrm{OH}^{-}(0.1 \mathrm{M})\right) .^{27}$ The structure of the anodic layer accumulated stepwise during the $\mathrm{ORC}$ in the $0-0.3-\mathrm{V}$ range has been assigned to that of a highly hydrous $\mathrm{Ag}(\mathrm{I})$ oxide layer. The electroreduction of this layer takes place at potentials lower than $0 \mathrm{~V}$ and yields an electroreduced $\mathrm{Ag}$ overlayer with a porous globular structure exhibiting a typical SEM micrograph (Figure 10). The structure of the Ag overlayer and its mechanism of formation are probably comparable to those reported recently for the structure and formation of $\mathrm{Pt}$ and $\mathrm{Au}$ electrodispersed electrodes. ${ }^{12,13}$ Briefly, the structure of the electrodispersed electrodes, as derived directly from ex situ STM images, consists of a piling up of sticking nearly spherical superclusters of about $10 \mathrm{~nm}$ in average diameter with interconnecting pores of about the same size. The surface to volume atom number ratio for each of those clusters is apparently the greatest one compatible with the metal bulk properties. Surfaces of this type resulting for $\mathrm{Pt}$ and $\mathrm{Au}^{12,13}$ exhibit typical surface plasmon spectra ${ }^{28}$ as well as adsorbate-substrate interactions for various simple molecules. ${ }^{29}$ For the case of SERS-active Ag surfaces, one should expect on the one hand particular adsorption interactions with $\mathrm{H}_{2} \mathrm{O}, \mathrm{OH}^{-}$ion, and $\mathrm{Py}$ and on the other the proper effects due to the photon-surface plasmon couplings at the metallic clusters modified by the electric field across the metal-electrolyte interface. ${ }^{30}$

In going to the SERS activation of $\mathrm{Ag}$, the proper method of ORC can produce distinguishable patches of electroreduced $\mathrm{Ag}$ with a certain degree of preferred crystallographic orientation, as is the case for other metals. ${ }^{31}$ In this respect distinguishable $\mathrm{H}_{2} \mathrm{O}, \mathrm{OH}^{-}$ion, and Py specific interactions with the different crystallographic faces should be expected, as each one of them is characterized by its own potential of zero charge. ${ }^{32-34}$

The possibility that a certain degree of monoorientation can be achieved during the ORC of Ag electrodes is inferred from the fact that the oxide layer formed in the first

(28) Lezna, R; de Tacconi, N. R.; Perdriel, C. E; Arvia, A. J. Proc Electrochem. Soc. Philadelphia Meeting, Spring, 1987.

(29) Marcos, M.; Vara, J. M.; Gonzâlez-Velasco, J.; Arvia, A. J. J. Electroanal. Chem. 1987, 224, 189.

(30) Otto, R. Festkorperprobleme 1982, 22.

(31) Chialvo, A. C.; Triaca, W. E.; Arvia, A. J. J. Electroanal. Chem. $1983,146,93$.

(32) Trasatti, S. J. Electroanal. Chem. 1984, 172, 27.

(33) Pettinger, B.; Philpott, M. R.; Gordon, J. R., II. J. Chem. Phys. $1981,74,934$

(34) Otto, A. In Surface Enhanced Raman Scattering; Chang, R. K., Furtak, T. E., Eds.; Plenum: New York, 1981; p 125. 
anodic scan starting with a fresh activated $\mathrm{Ag}$ electrode (Figure 9 ) contains only peak $A_{3}$, which has been reported as the main peak for $\mathrm{Ag}(111)$ under comparable conditions. This correlates with the fact that the capacity for oxygen adsorption, and hence, the hydrophilicity of Ag crystallographic faces, increases in the sequence $(110)<(100)<$ (111). ${ }^{32-34}$ The voltammetric profile of the (111)-type preferred monooriented Ag patches at freshly activated Ag apparently disappears gradually during voltammetric cycling between -0.4 and $0.9 \mathrm{~V}$ to approach the voltammogram characterizing the starting Ag surface (Figure 9).

SERS of Py on Ag in Alkaline Solution. The present results conclusively show that SERS can be produced in alkaline solutions in the absence of halide ions. This result indicates that in the $\mathrm{ORC}$ the $\mathrm{Ag}-\mathrm{OH}^{-}$ion interactions become comparable to the halide-silver surface interactions in order to promote the SERS activation of $\mathrm{Ag}$ electrodes. As a matter of fact this result is not surprising if one considers the structure of $\mathrm{OH}^{-}$ion, which can be considered a pseudo halide ion, although it has a polarizability smaller than that of $\mathrm{Cl}^{-}$ion $\left(\epsilon_{\mathrm{OH}^{-}}=4.9 \mathrm{~cm}^{3} \mathrm{~mol}^{-1}\right.$, $\left.\epsilon_{\mathrm{Cl}^{-}}=8.9 \mathrm{~cm}^{3} \mathrm{~mol}^{-1}\right)$. $^{35-37}$

The maximum SERS activity for Py appears with the maximum roughness factor observed in the potential range where the Ag electrode surface is supposedly completely electroreduced. The SEM micrograph shown in Figure 10 indicates an agreement with recently reported data ${ }^{10,11}$ in the sense that the morphology of the electrode involves a 2D surface concentration of roughness features and interfeature distance compatible with the most intense SERS response. Otherwise, SERS activity disappears when the potential enters into regions where faradaic reactions take place.

These results agree with the observation already made by different authors pointing out the close relationship between SERS and electrosurface modifications produced through ORC. ${ }^{1-11}$ The surface modifications involve the appearance of SERS and changes in the voltammetric profiles. The latter have been described in terms of two contributions, ${ }^{17}$ namely, a long time range effect $(t>30$ $\mathrm{min}$ ) that has been assigned to the proper increase in the electrode roughness and a short time range effect that corresponds to the greatest formation of highly reactive Ag sites with implied "atomic" or small-scale roughness as that observed, for instance, for Pt at the nanometer scale through STM after the site has been subjected to electrochemical facetting treatments. ${ }^{38,39}$ Presumably these sites are principally responsible for the changes produced in the HER.

The morphology of a Ag electrode surface is also extremely dependent upon the electrochemical treatment, ${ }^{40}$ including a potentiostatic treatment in alkaline solutions under stirring. The latter results in voltammetric changes observed afterwards in the HER and $\mathrm{Ag}(\mathrm{I})$ oxide formation already described in Characteristics of Ag Electrodes in this section.

The competitive interactions between $\mathrm{H}_{2} \mathrm{O}, \mathrm{OH}^{-}$ion, and $\mathrm{Py}$ for $\mathrm{Ag}$ sites can be considered a function of the applied potential, and as far as these interactions are concerned it is worthwhile noticing that the potential of zero charge of polycrystalline $\mathrm{Ag}$ at the solution $\mathrm{pH}$ lies in the neighborhood of $-0.77 \mathrm{~V}$ (vs $\mathrm{Hg} / \mathrm{HgO} / \mathrm{OH}^{-}$electrode) ${ }^{32}$ At this

(35) Heydweiller, A. Phys. Z. 1925, 26, 526.

(36) Fajans, K. Z. Phys. Chem. 1934, B24, 103

(37) Fajans, K. Z. Phys. Chem. 1941, 9, 281.

(38) Gómez, J. Vázquez, L.; Baró, A M. Garcia N; Perdriel, C. L. Triaca, W. E.; Arvia, A. J. Nature (London) 1986, 323, 612

(39) Vảzquez, L.; Gómez, J. M.; Gómez, J.; Baró, A. M.; Garcia, N.; Canullo, J. C.; Arvia, A. J. Surf. Sci. 1987, 181, 98. potential, which lies in the potential range where the maximum SERS intensity at $1008 \mathrm{~cm}^{-1}$ is observed (Figure 2), a maximum interaction between $\mathrm{Py}$ and $\mathrm{Ag}$ and a maximum resonance with the charge-transfer process should be expected. Accordingly, in the potential range comprised between $-0.77 \mathrm{~V}$ and the threshold potential of $\mathrm{Ag}(\mathrm{OH})_{\text {ad }}$ formation, as the applied potential is made increasingly positive the $\mathrm{Ag}-\mathrm{OH}^{-}$ion interaction becomes stronger. This means that in the electroreduction scan as the potential moves from $0.1 \mathrm{~V}$ downward to $-0.77 \mathrm{~V}$, the following subsequent processes can occur along the potential sweep. For $0.1 \mathrm{~V}>E>-0.77 \mathrm{~V}$ :

$$
\begin{gathered}
\mathrm{Ag} * \text { (oxide })+\mathrm{H}_{2} \mathrm{O}+\mathrm{e}^{-} \rightarrow \mathrm{Ag}^{*}\left(\mathrm{OH}^{-}\right) \\
\mathrm{Ag}^{*}\left(\mathrm{OH}^{-}\right)+\mathrm{Py} \rightarrow \mathrm{Ag}^{*}\left(\left(\mathrm{OH}^{-}\right) \mathrm{Py}\right)
\end{gathered}
$$

Reaction $3 \mathrm{a}$ corresponds to the oxide layer electroreduction yielding adsorbed $\mathrm{OH}^{-}$ions, and reaction $3 \mathrm{~b}$ represents the interaction of the $\mathrm{OH}^{-}$ion covered Ag surface with Py at certain adsorption sites denoted Ag*. Probably there is some contribution to the SERS of $\mathrm{OH}^{-}$ion adsorption in this potential region, which can be related to the peak in the SERS intensity vs $E_{\mathrm{h}}$ plot (Figure 2) at ca. $0.15-0.20$ $V$ for the band at $1038 \mathrm{~cm}^{-1}$ and the relative high SERS intensity still observed for more positive $E_{\mathrm{h}}$ values, although at present this is only a conjecture and deserves further research. At $E \approx-0.77 \mathrm{~V}$

$\mathrm{Ag}^{*}\left(\mathrm{OH}^{-}\right)+\mathrm{H}_{2} \mathrm{O}+\mathrm{Py} \rightarrow \mathrm{Ag} *\left(\mathrm{Py}\left(\mathrm{H}_{2} \mathrm{O}\right)\right)+\mathrm{OH}^{-}$

that is, a competitive adsorption of $\mathrm{OH}^{-}$ion, $\mathrm{H}_{2} \mathrm{O}$, and $\mathrm{Py}$ molecule at $\mathrm{Ag}^{*}$ is established where a net prevalence of adsorbed polar molecules at the $\mathrm{Ag}$ surface site should occur. These species have different strengths of adsorption at $\mathrm{Ag}$ surface and, therefore, different chemical properties, which should reflect in the chemical effects. In terms of a charge-transfer model competitive adsorption brings a complicated contribution of modifiers of energy levels at specific microscopic sites (atomic-scale roughness) of the substrate ${ }^{40}$ where charge transfer is supposed to occur.

Finally, at $E<-0.77 \mathrm{~V}$, Py becomes less strongly adsorbed on $\mathrm{Ag}$, leading to deactivation of the electrode with respect to SERS ability. This effect also modifies the rate of the HER. The overall reaction can be represented as follows:

$$
\mathrm{Ag} *\left(\mathrm{Py}\left(\mathrm{H}_{2} \mathrm{O}\right)\right)+\mathrm{H}_{2} \mathrm{O}+2 \mathrm{e}^{-} \rightarrow \mathrm{Ag}(\mathrm{Py})+2 \mathrm{OH}^{-}+\mathrm{H}_{2}
$$

Reaction $3 \mathrm{~d}$ implies a deactivation of the Ag electrode surface not only for the HER but also a change in the interaction between $\mathrm{Py}$ and $\mathrm{Ag}$ through $\mathrm{OH}^{-}$ion and $\mathrm{H}_{2} \mathrm{O}$. It has already been established that a partial deactivation of $\mathrm{Ag}$ electrode can be produced through the adsorption of the metal atoms, and the processes imply simultaneously a loss of both large-scale and atomic-scale roughness. ${ }^{20,40}$

The fact that at ca. $-0.77 \mathrm{~V}$ the SERS intensity of Py is only a little different in the location and distribution of the absorption bands as compared to the Raman spectra of $\mathrm{Py}$ in solution is consistent with the idea that the Ag-Py interaction occurs at the electrode surface level without a considerable distortion of Py molecule. ${ }^{24}$

SERS Intensity of Py Potential Dependence. Another relevant feature of SERS is the dependence of band intensities on the potential applied to the electrode. The band at $1008 \mathrm{~cm}^{-1}$, which corresponds to the symmetric breathing vibration of the ring, exhibits a maximum intensity in the potential range between -0.5 and $-0.6 \mathrm{~V}$.

(40) Tuschel, D. D.; Pemberton, J. E.; Cook, J. E. Langmuir 1986, 2, 380 
Otherwise, the intensity of the asymmetric breathing vibration mode of the ring (1038- $\mathrm{cm}^{-1}$ band) changes in a rather complex way with the potential. This dependence probably corresponds to two overlapping effects, one with its maximum value at ca. $-0.2 \mathrm{~V}$ and another one with a wide maximum at about $-0.5 \mathrm{~V}$. The first function can be related to the potential region where the local $\mathrm{OH}^{-}$ion concentration at the interface is rather high whereas the second one develops around the pzc. The bands at 1215 and $625 \mathrm{~cm}^{-1}$ both present maxima in the band intensity vs potential plot (Figure 2): the first one in the -0.7 to -0.8 $\mathrm{V}$ range and the second one at ca. $-0.6 \mathrm{~V}$, that is, in the vicinity of the pzc. Therefore, as far as the influence of the potential on the band intensities is concerned, one concludes that the symmetric modes behave rather similarly in contrast with the asymmetric modes. This difference presumably implies a configuration change in the adsorbate depending on the solution composition, which would reflect the influence of chemical contributions to SERS through the charge transfer between Ag and adsorbate sites of atomic-scale roughness. ${ }^{41-43}$ However, to verify this suggestion further data on the $\mathrm{pH}$ influence on Py spectra of Ag are required, including more detailed information about the electrochemistry of the $\mathrm{Ag} / \mathrm{Py}$ interface. These matters will be dealt with in a forthcoming publication.

(41) Burstein, E.; Chen, Y. J.; Chen, C. Y.; Lundquist, S.; Tossatti, E. Solid State Commun. 1979, 29, 567.

(42) Gersten, J. I.; Birke, R. L.; Lombardi, J. R. Phys. Rev. Lett. 1979, $43,147$.

(43) Otto, A. Appl. Surf. Sci. 1980, 6, 309

\section{Conclusion}

SERS of Py on Ag electrodes can be produced in alkaline solutions free of halide ions. SERS activation of Ag implies a certain metal roughness resulting from ORC treatment covering the potential range between the $\mathrm{Ag} / \mathrm{AgOH} / \mathrm{OH}^{-}$ and $\mathrm{Ag} / \mathrm{AgO} / \mathrm{OH}^{-}$redox equilibrium potentials. The electroreduced SERS-active Ag surface presents a rather uniform globular structure as revealed through SEM. Voltammetric data also indicate an appreciable degree of preferred crystallographic orientation at the initially reduced Ag surface with development of (111) faces. SERS band intensities change with the applied potential. A maximum absorption for the symmetric mode can be observed in the vicinity of the pzc. SERS appears to be related to a rather complex interaction between $\mathrm{Py}, \mathrm{H}_{2} \mathrm{O}$, and $\mathrm{OH}^{-}$ions with active $\mathrm{Ag}$ surface sites. In general, at potentials lower than $-1.0 \mathrm{~V}$ the SERS effect is inhibited irreversibly in the base solution due to loss of atomic-scale roughness. SERS inhibition occurs parallel with the increase in the efficiency for the HER, resulting through the potential holding of $\mathrm{Ag}$ in the alkaline solution as reported previously. ${ }^{17}$

Acknowledgment. This work was in part supported by FAPESP, CNPq, and FINEP (Brazil) and by CONICET, CIC (Pcia. Bs. As.), and CONICOR (Argentina). G.I.L. is indebted to CNPq/CONICET for the fellowship granted.

Registry No. Py, 110-86-1; Ag, 7440-22-4; $\mathrm{H}_{2} \mathrm{O}, 7732-18-5 ; \mathrm{OH}^{-}$, 14280-30-9; $\mathrm{H}_{2}$, 1333-74-0; NaOH, 1310-73-2.

\title{
NMR Relaxation in Micelles Formed by a Long Zwitterionic Surfactant
}

\author{
O. Söderman, ${ }^{*}{ }^{\dagger}$ G. Carlström, ${ }^{\dagger}$ M. Monduzzi, ${ }^{\ddagger}$ and U. Olsson ${ }^{\dagger}$ \\ Department of Physical Chemistry 1, University of Lund, P.O.B. 124, S-221 00 Lund, Sweden, \\ and Department of Chemistry, University of Cagliari, Via Ospedale 72, Cagliari, Italy \\ Received October 30, 1987. In Final Form: March 15, 1988
}

\begin{abstract}
A frequency-dependent ${ }^{14} \mathrm{~N}$ and ${ }^{13} \mathrm{C}$ NMR relaxation study of the micellar region formed by a very long zwitterionic surfactant, viz., 6-(dimethyleicosylammonio)hexanoate $\left(\mathrm{C}_{20} \mathrm{AH}\right)$, is presented. As a starting point the binary phase diagram of $\mathrm{C}_{20} \mathrm{AH} / \mathrm{D}_{2} \mathrm{O}$ is determined. The phase diagram is similar to those found for shorter chain ionic surfactants with bulky head groups. The NMR relaxation data show a dependence upon the magnetic field strength and are discussed in terms of the two-step model of relaxation. The frequency dependence found at low frequencies in the ${ }^{14} \mathrm{~N}$ data is assumed to be caused by the rotational tumbling of the micelle, while it is argued that the frequency dependence found at high frequencies in the ${ }^{13} \mathrm{C}$ relaxation data is caused by a local motion. The analysis of the data yields a radius of the micelle which is slightly shorter than an extended $\mathrm{C}_{20}$ chain, pointing to a situation where the methylene groups in the head-group dipole are embedded in the micelle. Moreover, the local motions in the head-group region are slow as compared to the corresponding motions in single-chain ionic surfactants.
\end{abstract}

\section{Introduction}

Nuclear magnetic resonance (NMR) techniques have proved to be very valuable in providing information on the structure and dynamic behavior of surfactants in micellar aggregates as well as in cubic, hexagonal, or lamellar phases. ${ }^{1-3}$ In particular, the use of different nuclei such as ${ }^{2} \mathrm{H},{ }^{13} \mathrm{C}$, and ${ }^{14} \mathrm{~N}$ provides complementary details concerning the possible kinds of motions that may occur in

\footnotetext{
${ }^{\dagger}$ University of Lund.

University of Cagliari.
}

different phases. A general observation in the study of isotropic surfactant systems is that the spin-lattice relaxation times depend on the field strength and that they

(1) Tiddy, G. In Nuclear Magnetic Resonance; Webb, G. A., Ed. Specialist Periodical Reports, Royal Society of Chemistry: London, 1981; Vol. 10 , p 267.

(2) Söderman, O. In Nuclear Magnetic Resonance; Webb, G. A., Ed.; Specialist Periodical Reports, Royal Society of Chemistry: London, 1985; Vol. 12 , 350

(3) Khan, A. In Nuclear Magnetic Resonance; Webb, G. A., Ed.; Specialist Periodical Reports, Royal Society of Chemistry: London, 1987; Vol. $16, \mathrm{p} 414$. 